\title{
DEVELOPMENT AND VALIDATION OF UV-SPECTROSCOPIC METHOD FOR ESTIMATION OF TIOTROPIUM BROMIDE IN API AND PHARMACEUTICAL DOSAGE FORM
}

\author{
ANJALI P. KOKANE*, BHAGYASHRI S. SHINDE, M. S. KALSHETTI
}

Department of Pharmaceutical Quality Assurance, D. S. T. S Mandal's College of Pharmacy, Solapur, Maharashtra, India Email: anjalikokane333@gmail.com

Received: 18 Jun 2020, Revised and Accepted: 19 Aug 2020

\section{ABSTRACT}

Objective: The current work intended towards the developed and validated UV spectrophotometric method for the estimation of Tiotropium Bromide in API and pharmaceutical formulation.

Methods: The UV spectrum of tiotropium bromide in methanol shows maximum absorbance at $230 \mathrm{~nm}$. Calibration curve method was used for the estimation of tiotropium bromide in API and pharmaceutical formulation.

Results: Maximum absorbance obtained in $230 \mathrm{~nm}$. Calibration curve plotted in concentration range $20-120 \mu \mathrm{m} / \mathrm{ml}$ exhibit the linearity relationship with line equation $\mathrm{y}=0.0057 \mathrm{x}+0.3319$. The Accuracy was found to be $80-100.5 \%$. The precision $\% \mathrm{RSD}=0.1110$, and the limit of detection(LOD) $=4.12$ and limit of quantification $(\mathrm{LOQ}=12.50$. The method was found to comply all the validation parameters as per the $\mathrm{ICH}$ guideline in indicating the sensitivity of the method analyte.

Conclusion: This method is used as satisfactory for the routine analysis of tiotropium bromide in API and pharmaceutical dosage forms.

Keywords: Tiotropium bromide, UV Spectrophotometer, Methanol, Validation

(C) 2020 The Authors. Published by Innovare Academic Sciences Pvt Ltd. This is an open access article under the CC BY license (http://creativecommons.org/licenses/by/4.0/] DOI: http://dx.doi.org/10.22159/ijcpr.2020v12i5.39767. Journal homepage: https://innovareacademics.in/journals/index.php/ijcpr

\section{INTRODUCTION}

The Tiotropium Bromide chemically is $(1 \propto, 2 \beta, 4 \beta, 5 \propto, 7 \beta)-7-$, [(Hydroxydi-2-thieyl-acetyl) oxy]-9, 9-dimethyl-3-oxa-9-azoniatricyclo [3.3.1.0] [1]. Tiotropium is used as a maintenance treatment of chronic obstructive pulmonary disease (COPD). It may also be used as an addon-therapy in people with moderate-to-severe asthma on medium to high dose inhaled corticosteroid (ICS) $[2,3]$ Tiotropium bromide smooth muscles relaxation and bronchodilation [4,5]. A tiotropium metered inhalation spray is indicated for the maintenance of bronchospasms in COPD to prevent exacerbation of COPD and to treat asthma in patient six or more year old $[6,7]$. It is used by inhalation through the mouth $[8,9]$. Onset typically begins within half an hour and lasts for $24 \mathrm{~h}$. It is not, however, approved for acute exacerbation of COPD or acute worsening asthma $[10,11]$.

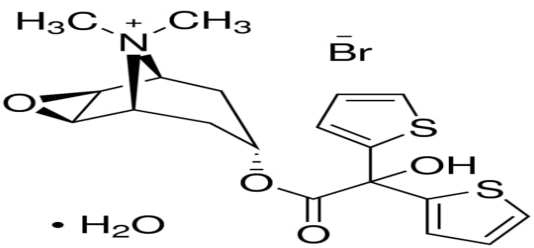

Fig. 1: Chemical structure of tiotropium bromide [1]

\section{MATERIALS AND METHODS}

\section{Selection of solvent and instrument}

Tiotropium bromide is dissolving in various solvents for trails of selecting the ideal solvent $[12,13]$. Various solvents i.e. methanol water, ethanol, acetonitrile. Tiotropium bromide is soluble in methanol, and better absorption was found to be at230 nm. UVVisible Spectrophotometer (shimadzu AY220) [14-16]. Reagents and Materials is API-Tiotropium Bromide was obtained as a gift sample from the Vamsi Pharmaceutical Ltd. Solapur, Maharashtra. Capsule is purchased from the local pharmacy in Solapur. Brand name is Tiova (Cipla); methanol was used for this study.

Experimental work

Method development

Selection of detection wavelength

Dilution of Tiotropium bromide was prepared from the stock solution $(50 \mu \mathrm{g})$. Tiotropium bromide was scanned over a range of 200-400 nm. Drug showed maximum absorbance at $230 \mathrm{~nm}$ was selected as the wavelength for detection.

\section{Preparation of standard drug solution}

$10 \mathrm{mg}$ of Tiotropium bromide was weighed and transferred into a $10 \mathrm{ml}$ volumetric flask containing methanol. Concentration of stock solution is $(1000 \mu \mathrm{g} / \mathrm{ml})$. Then pipette out $2 \mathrm{ml}$ form the stock solution and adjust to volume.

\section{RESULTS AND DISCUSSION}

\section{Method validation}

The method was validated for several parameters like a preliminary analysis of drug Linearity, Accuracy, Precision, Robustness, Ruggedness, Limit of Detection, Limit of Quantification and specificity of tiotropium bromide.

\section{Preliminary analysis of drug}

Observation and result of preliminary analysis of Tiotropium bromide.

Preliminary analysis of drug

\begin{tabular}{lll}
\hline Test & Observation & Result \\
\hline Description & White powder & Complies \\
Solubility & $\begin{array}{l}\text { Soluble in methanol } \\
\text { and acetonitrile }\end{array}$ & Complies \\
& & \\
\hline
\end{tabular}

The UV-Spectrum of Tiotropium bromide in methanol showed at max absorbance at $230 \mathrm{~nm}$. 


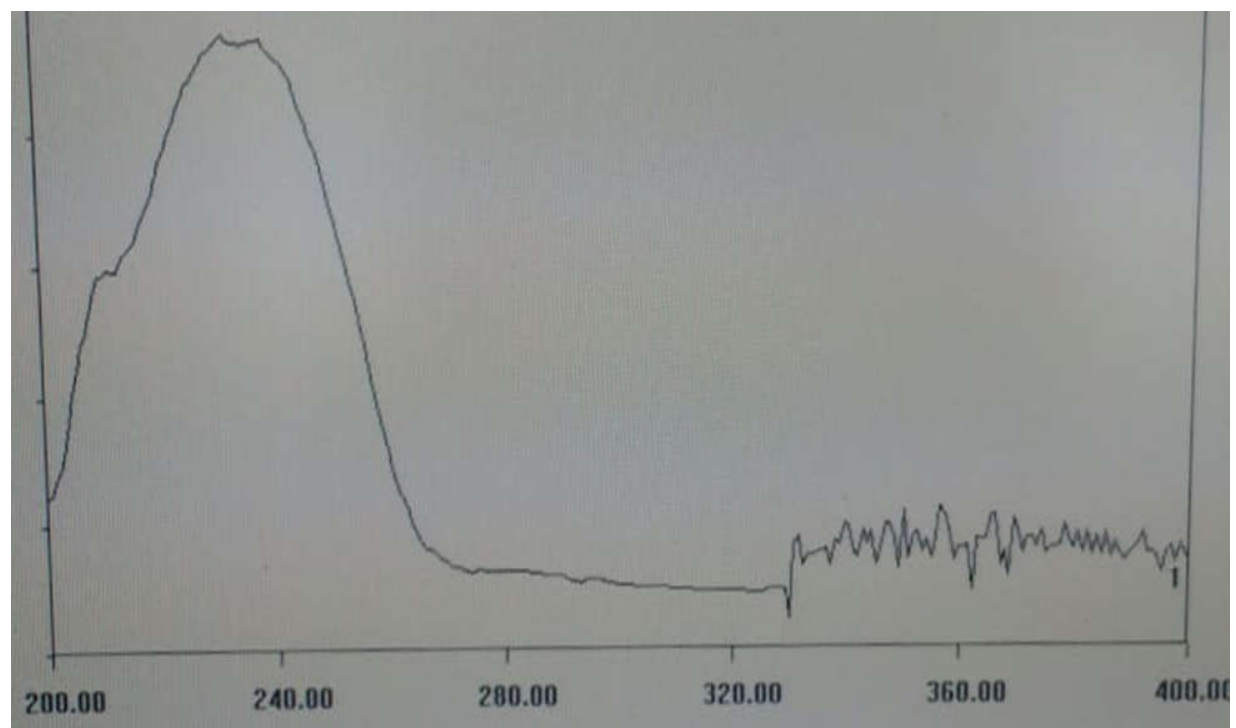

Fig. 2: UV visible spectrophotometer graph of tiotropium bromide

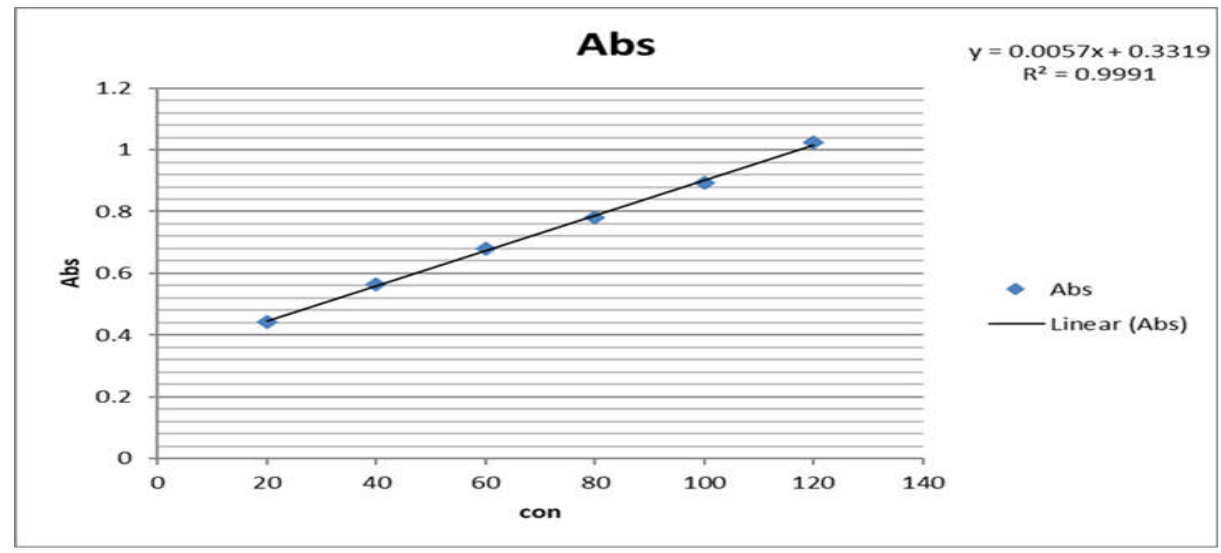

Fig. 3: Calibration curve for tiotropium bromide

\section{Linearity and range}

It is a linear relation between absorbance and concentration of drug was evaluated using three replicates over concentration range in 20 $120(\mu \mathrm{g} / \mathrm{ml})$ by making the replicates (fig. 3)

The wavelength for linearity was scanned at $230 \mathrm{~nm}$. By taking five different concentrations for linearity the regression coefficient was found to 0.999 i.e. in the limit of standard. Hence linearity was found to be validated.

\section{Accuracy}

This study was carried out at three different levels that are $80 \%$, $100 \%, 120 \%$, by standard addition method. Analyzed sample by triplicate by according to the method. Known amount of standard tiotropium bromide was spike on the capsule sample. Check the absorbance and calculated (table 1)

\section{Precision}

Precision is defined as an analytical procedure is define the closeness of agreement between samples of measurements obtained from multiple sampling of the same homogenous sampling in specific conditions. It is determined by inter-day. Reading is taking 3 times on the same day. The percent relative standard deviation. (\%RSD) was calculated (table 2)

\section{Robustness}

Robustness is a measure of its capacity of analytical procedure to remain unaffected by small changes or this method small deliberate variation in the method parameters. Main aim of this test is to create a method that allow for some variations in the parameters. In this study wavelength was change at $\pm 5 \mathrm{~nm}$. Then robustness is calculated.

Table 1: Result of accuracy

\begin{tabular}{lllllll}
\hline S. No. & \% level & Spike amount $(\boldsymbol{\mu g} / \mathbf{m l})$ & Spiked amount (wrt sample) & Abs. & Amount recovered & \%RSD \% recovery \\
\hline 1 & 80 & 79.440 & 79.4 & 0.829 & 80.651 \\
2 & 100 & 99.300 & 99.3 & 1.051 & 100.550 \\
3 & 120 & 119.160 & 119.2 & 1.227 & 100.5 & 0.9 \\
\hline
\end{tabular}


Table 2: Result of intra-day morning precision

\begin{tabular}{llll}
\hline S. No. & Concentration $(\mu \mathrm{g} / \mathbf{m l})$ & Absorbance & SD \\
\hline 1 & 60 & 0.678 & \\
2 & 60 & 0.679 & \\
3 & 60 & 0.679 & 0.000753 \\
4 & 60 & 0.678 & \\
5 & 60 & 0.677 & 0.111028 \\
6 & 60 & 0.678 & \\
\hline
\end{tabular}

Table 3: Result of robustness

\begin{tabular}{|c|c|c|c|c|}
\hline S. No. & Wavelength & Absorbance & SD & \%RSD \\
\hline \multirow[t]{4}{*}{1} & 230 & 0.444 & & \\
\hline & & 0.434 & 0.006083 & 1.3919 \\
\hline & & 0.433 & & \\
\hline & & Avg $=0.43$ & & \\
\hline \multirow[t]{4}{*}{2} & 232 & 0.432 & & \\
\hline & & 0.434 & 0.005859 & 1.3428 \\
\hline & & 0.443 & & \\
\hline & & $A v g=0.436$ & & \\
\hline
\end{tabular}

By change in wavelength i.e. $232 \mathrm{~nm} . \%$ RSD is less than $2 \%$ i.e. within the range. So parameter was validated (table 3 )

\section{Ruggedness}

Ruggedness is defined as, reproducibility of the results when the defined method was performed under different analysts, laboratories, columns, chemicals, solvents, instruments, sources of reagents and etc.

\section{Limit of detection}

Detection limit is defined as, the lowest amount of analyte in a sample can be detected (table 6)

$\mathrm{LOD}=3.3(\mathrm{SD} / \mathrm{S}) \mathrm{SD}=$ Standard deviation, $\mathrm{S}=$ slope of the curve

Table 4: Result of ruggedness

\begin{tabular}{lll}
\hline Concentration $(\boldsymbol{\mu g} / \mathbf{m l})$ & Absorbance & Statistical analysis \\
\hline 60 & 0.678 & Avg $=0.678$ \\
60 & 0.679 & SD $=0.001$ \\
60 & 0.677 & $\%$ RSD $=0.147$ \\
\hline
\end{tabular}

Table 5: Result of ruggedness

\begin{tabular}{lll}
\hline Concentration $(\mu \mathrm{g} / \mathbf{m l})$ & Absorbance & Statistical analysis \\
\hline 60 & 0.679 & Avg $=0.678$ \\
60 & 0.678 & SD $=0.001$ \\
60 & 0.677 & $\%$ RSD $=0.147$ \\
\hline
\end{tabular}

By change in analyst and laboratory, there is no effect on absorbance with same conditions; hence, parameter was validated (table 4 and 5).

Table 6: Result of limit of detection

\begin{tabular}{lc}
\hline $\mathrm{LOD}(\mu \mathrm{g} / \mathrm{ml})$ & 4.12 \\
\hline & Table 7: Result of limit of quantification \\
\hline $\mathrm{LOQ}(\mu \mathrm{g} / \mathrm{ml})$ & 12.50 \\
\hline
\end{tabular}

\section{Limit of quantitation [17]}

Limit of quantification is defined as; it is an individual analytical procedure is the lowest amount of an analyte in the sample, which can be an exact value (table 7)

$\mathrm{LOQ}=10(\mathrm{SD} / \mathrm{S}) \mathrm{SD}=$ Standard deviation, $\mathrm{S}=$ slope of the curve

\section{CONCLUSION}

The proposed method is found to be accurate, precise, stable, linear, specific, and simple for quantitative estimation of tiotropium bromide in the bulk and pharmaceutical dosage form. Hence the present method is suitable for the routine assay of tiotropium bromide in bulk and pharmaceutical formulation.

\section{ACKNOWLEDGEMENT}

Authors are thankful to the D. S. T. S. Mandal's College of Pharmacy, Solapur. Maharashtra India for providing the facility for the conduct of the research work. Authors are also thankful to Prof. Dr. M. S. Kalshetti for their consistent support and assistance throughout the project work.

\section{FUNDING}

Nil

\section{AUTHORS CONTRIBUTIONS}

All the authors have contributed equally. 


\section{CONFLICT OF INTERESTS}

Declared none

\section{REFERENCES}

1. S Priyanka, M Anuradha, Kavita Waghray. A novel analytical method development and validation of Tiotropium bromide and formaterol fumarate pharmaceutical dosage form by using RP-HPLC method. Int J Curr Trend's Pharm Res 2019;7:25-30.

2. Anuja S Nevse, Savita Yadav, Ravindra Purohit, Janhavi R Rao. Development and validation of HPTLC method for estimation of Tiotropium bromide monohydrate in dry powder inhalation dosage form. World J Pharm Pharm Sci 2016;5:795-802.

3. Suthakaram R, Bikshapathi D, Sudha Parimala. Rp-HPLC method development and validation for quantitative estimation of Tiotropium bromide and oldaterol. Int J Biomed Investigation 2018;1:2581-4745.

4. Raman N Kanchave, Sanjay R Chaudhari, Mayura Kale, Rajendra D Wagh. Simultaneous estimation of formaterol fumarate and tiotropium bromide by RP-HPLC in dry powder inhaler. Inventi J 2013;4:976-3813.

5. Ravi P Pulla, BS Sastry, Y Rajendra Prasad, N Appala Raju. RPHPLC method for simultaneous estimation of formatero fumarate, tiotropium bromide and ciclesonide in pharmaceutical metered dose inhalers. Asian J Res Chem 2011;4:585-90.

6. K Srinivasu, J Venkateswara Rao, N Appala, K Mukkanti. Simultaneous RP-HPLC method for the estimation of formaterol fumarate and Tiotropium bromide in the pharmaceutical dosage form. Asian J Chem 2010;22:3943-8.

7. Ehab Farouk Elkady, Marwa Hosnytammam, Ayman Abo Elmaaty. Development and validation of RP-HPLC method for simultaneous estimation of tiotropium bromide, formaterol fumarate and olodaterate HCL in bulk and method dose aerosols, application to olodaterol HLC forced degradation study and degradation kinetics. Springer; 2017.

8. ICH, Q2 (R1) Validation of analytical procedures: text and methodology, International conference on harmonization; 1996.
9. Dave Sign, Arjun Ravi, Katie Kane, Tess Schmalbach, Dvid L Hava. The pharmacokinetics, pharmacodynamics and tolerability of PUR0200, A novel tiotropium formulation in chronic obstructive pulmonary disease. Br Clin Pharmacol 2018;84:2097-105.

10. Bhairam Bhoomalah, Anireddy Jayashree. Simultaneous quantification of olodaterol and tiotropium bromide by highperformance liquid chromatography. Asian J Chem 2017;29:145.

11. Sunita Sule, Sushma Ambadekar, Abhay Singh, Phalguni Naik. A rapid and stability-indicating RP-HPLC method for simultaneous determination of tiotropium bromide, formaterol and ciclesonide in a dry powder inhaler. World J Pharm Res 2014;3:819-30.

12. Jngduan Chi, Fumin Li, Rand Jenkins. Ultrasensitive sub-pg/ml. Determination of tiotropium bromide in human plasma by 2D HPLC-MS/MS. Challenges Solution 2016;8:385-95.

13. Jaime Algorta, Laura Andrade, Marte Medna, Valentin Kirkov, Sacha Arsova, Fumine Li. Pharmacokinetic bioequivalence of two inhaled tiotropium bromide formulation in healthy volunteers. Springer 2016;36:753-62

14. Jung Sunwoo, Su-Jin Rhee, Seung Hwan Lee, In-Jn Jang. Pharmacokinetic characteristics of fluticasone, salmeterol, and tiotropium after concurrent inhalation. Transl Clin Pharmacol(TCP) 2017;25:85-92.

15. BD Shah, Susu Kumar, Yogesh C Yada. Analytical method development and validation of tiotropium bromide and formaterol fumarate metered-dose inhaler by using RP-HPLC method. Asian J Biochem Pharm Res 2011;1:145-58.

16. Anjali P Kokane, Varsha Tegeli, Bhagyashri S Shinde. UV spectroscopy method development and Validation for estimation of Ipratropium bromide in API and pharmaceutical dosage form. Int J Chem Pharm Res 2020;12:69-73.

17. Mohammed bouhajb, Zia Tazd. An evaluation of the pharmacokinetics of tiotropium following a single-dose inhalation in healthy subjects using an ultra-sensitive bioanalytical method. Taylor Francis Online 2019;45:1915-20. 